\title{
Integrated Management of Childhood Illness strategy implementation in a rural district of Pakistan through the lens of planners and implementers
}

\author{
Nousheen Akber Pradhan*1, Nick Brown ${ }^{2}$, Neelofar Sami ${ }^{3}$, Narjis Rizvi ${ }^{1}$ \\ ${ }^{1}$ Department of Community Health Sciences, Aga Khan University, Karachi, Pakistan \\ ${ }^{2}$ Salsbury District Hospital Wiltshire, United Kingdom \\ ${ }^{3}$ Willows Foundation, Pakistan
}

Received: June 24, 2015

Accepted: February 23, $2016 \quad$ Online Published: March 22, 2016

DOI: $10.5430 /$ ijh.v2n1p139

URL: http://dx.doi.org/10.5430/ijh.v2n1p139

\begin{abstract}
Objective: Integrated Management of Childhood Illness (IMCI) strategy aims to reduce under-five morbidity and mortality in developing countries. This qualitative study aimed to explore and analyze stakeholders' perceptions about IMCI implementation process at Primary Health Care facilities in Matiari district, Sindh Province, Pakistan.

Methods: This study used qualitative exploratory design. Through purposive sampling technique, eight stakeholders particularly involved in IMCI implementation process at district $(n=3)$ and provincial level $(n=5)$ were recruited for in-depth interviews. Interview data was manually transcribed and analyzed using content analysis.

Results: The interviews provided information on factors supporting and constraining IMCI implementation process. Stakeholders' perception of the significance of the strategy was the single most influential support factor. Constraint factors mainly consist of discrepancies in views toward the lead role in implementation, trained physicians' lack of willingness to practice IMCI strategy (as perceived by the stakeholders), inadequate logistic support, weak monitoring and supervisory system, lack of awareness about IMCI drugs and supplies, hindrances in the reporting system and corruption in the district health system affecting the practice of IMCI trained physicians.

Conclusions: The study showed inadequate health system support for IMCI implementation in the district with major discrepancies in views amongst planners and implementers toward IMCI implementation process. We recommend Provincial Maternal Neonatal and Child Health Program to synchronize the implementation process and provide necessary support to the district in IMCI implementation.
\end{abstract}

Key Words: Integrated Management of Childhood Illness, District Matiari, Pakistan, Support and constraint factors, Inadequate health system support, Planners and implementers

\section{INTRODUCTION}

Under-five mortality has decreased by almost $50 \%$ worldwide. ${ }^{[1]}$ However, preventable and treatable diseases needlessly kill young children. ${ }^{[1]}$ Of these, the commonest causes are respiratory infections, pneumonia (19\%), diarrhea $(18 \%)$, malaria (8\%), measles $(4 \%)$, and neonatal conditions $(37 \%) .^{[2]}$ Malnutrition is associated with $35 \%$ of deaths in children under-five. ${ }^{[2]}$ Integrated Management of Child-

\footnotetext{
* Correspondence: Nousheen Akber Pradhan; Email: nousheen.pradhan@aku.edu; Address: Department of Community Health Sciences, Aga Khan University, Stadium Road, PO Box. 3500, Karachi, Pakistan.
} 
hood Illness (IMCI) is a child survival strategy launched by WHO and UNICEF in 1995. ${ }^{[3]}$ The strategy aims to reduce under-five morbidities and mortalities in developing countries through an integrated approach by encompassing preventive and curative interventions. ${ }^{[4]}$ IMCI strategy pertains to improve: case management skills, health system support, and family and community practices for child health and development. ${ }^{[5]}$ Though over 113 countries have adapted the strategy, but the impact has been variable. ${ }^{[6]}$

There is a need for adequate health system support for effective IMCI implementation. ${ }^{[6,7]}$ This demands political will, training exposure of health workers, adequate availability of logistics, equipment and drugs, systematic follow up of trained workforce and an efficient referral system. ${ }^{[6,8]}$ Factors hindering implementation include: inadequate availability of supplies and drugs, infrequent supervisory visits and non- compliance to IMCI algorithms by trained workforce and inefficient referral system. ${ }^{[9-11]}$ Furthermore, poor commitment and ownership of IMCI at the national level, has also acted as a significant constraint to IMCI implementation. ${ }^{[12]}$ IMCI is often portrayed as a vertical rather than an integrated programme. A number of countries have responded to the challenge by investing efforts at strategic and operational level to facilitate the implementation process and also to scale up the implementation coverage. ${ }^{[7]}$

Pakistan is a low middle income country with a population of over 190 million. ${ }^{[13]}$ The Ministry of Health $(\mathrm{MoH})$ of Pakistan is devolved to provinces under a constitutional amendment. ${ }^{[14]}$ The health care is provided through three-tiered heath care delivery system. ${ }^{[15]}$ In order to curb the burden of preventable deaths among under-five year old children, $\mathrm{MoH}$ endorsed IMCI strategy in 1990s. ${ }^{[16]}$ It was subsequently scale up with the support of various partners including the National Maternal Neonatal and Child Health (NMNCH) program. ${ }^{[17]}$ District implementation status in 2011 showed that 95 out of 135 (70.4\%) districts initiated IMCI implementation, ${ }^{[17]}$ nevertheless, under five mortalities remain unacceptably high. Pakistan is one of only five countries in the world which account for half of the burden of under-five year deaths. ${ }^{[18]}$

A number of studies have assessed trained health workers' compliance with IMCI strategy, the need for training, health facility support for IMCI implementation and its overall impact on quality of child care. ${ }^{[3,9-11,31]}$ However, planners and implementers' perspectives concerning the factors influencing strategy implementation in Pakistan and in other developing countries has not received much attention. Keeping in view the complex health system issues in Pakistan, it is extremely significant to understand key stakeholders' perspective concerning IMCI implementation to reduce preventable morbidities and mortalities in children under-five.

We therefore explored stakeholders (planners and implementers) perceptions with an objective to identify enabling and constraining factors influencing IMCI implementation process at first level care PHC facilities in a rural district in Pakistan.

A better knowledge of stakeholders' understanding of the strategy, their perceived role in implementation, and their perceptions of the overall health system support are crucial in understanding potential factors affecting IMCI implementation. This will additionally help in proposing strategies to strengthen support factors and to overcome barriers at district level to ensure smooth implementation of the strategy.

\section{Methods}

\subsection{Study design and setting}

Obtaining planners and implementers' perspective was part of the larger mixed method study; to explore the factors influencing facility-based IMCI implementation at public sector PHC facilities in Matiari, district of Sindh Province, Pakistan ${ }^{[19]}$ Matiari is a rural district and is subdivided into three talukas. This district was amongst the first to initiate IMCI implementation in Sindh Province in 2006. The Ethical Review Committee of the Aga Khan University, Karachi, Pakistan granted approval for conducting this study. Administrative approval for the conduct of study was obtained from Executive District Officer- Health (EDO-H), Matiari, district. The duration of the study was July - September 2009.

\subsection{Data collection}

Key stakeholders were purposively selected for in-depth interviews. They included five provincial level (planners/policy makers) and three district level (managers and implementers) respondents. The characteristics of study participants are shown in Table 1.

Participants were interviewed face-to-face by NP in their office. A semi-structured interview guide was used to assess planners and implementers' comprehension of IMCI strategy, their perceived role and responsibilities toward implementation and challenges (if any) faced in the current district health system. An attempt was also made to understand their perceptions about the trained workforce in the district. Probes were used in a semi-structured guide for a further in-depth exploration of respondents' responses. The respondent's preference for the medium of communication was considered during interview. It was carried out in both English and Urdu languages. Interviews lasted between 60-90 minutes with a mean of 85 minutes. All ethical consideration were 
duly considered throughout the study i.e., obtained written consent prior to interviewing, privacy was maintained and responses were audio recorded with respondents' permission. All interviews were transcribed and translated into English language including verbatims. Confidentiality of the data was ensured by safely securing the information with access restricted only to first author.

Table 1. Characteristics of respondents

\begin{tabular}{|c|c|c|c|c|}
\hline S.\# & Respondents & Level & Gender & Training in IMCI \\
\hline P1. & Project Director, Maternal, Neonatal and Child Health Program, Sindh & & Female & Trained \\
\hline P2. & Child and Adolescent Health Officer for Pakistan, World Health Organization & & Male & Trained \\
\hline P3. & Project Director, People’s Primary Healthcare Initiative & Provincial & Male & Not trained \\
\hline P4. & Program Manager, Child Health & & Male & Not Trained \\
\hline P5. & Professor Pediatric Unit, Civil Hospital Karachi & & Male & Trained \\
\hline D1. & Executive District Officer Health (EDO-H) & & Male & Not Trained \\
\hline D2. & District Focal Person and Facilitator & District & Male & Not Trained \\
\hline D3. & District Health Officer Medical and Public Health & & Male & Not Trained \\
\hline
\end{tabular}

\subsection{Data analysis}

Data analysis was carried out manually. A careful review of transcribed interview data led to content analysis which remained the key feature of qualitative data analysis. Content analysis divides the entire text into manifest content (what text says) and latent content (underlying meaning of the text). ${ }^{[20]}$ Once an understanding of the data was acquired, the text was analyzed into meaning units, condensed meaning units and codes to capture the perceptions of stakeholders on factors affecting the implementation process. All codes were later grouped into eight categories to capture the manifest part. Lastly, the categories were merged into two themes: (1) support factor and (2) constraint factors for IMCI implementation (see Table 2). Figure 1 reflects an example of the analysis process described above.

Table 2. Themes and categories

\begin{tabular}{ll}
\hline Theme & Categories \\
\hline Support Factor for IMCI Implementation & Significance of IMCI strategy \\
& Disparities in views towards lead role in implementation \\
& IMCI trained physicians' willingness to practice IMCI strategy \\
& Inadequate logistic support \\
Constraint Factors for IMCI Implementation & Lack of awareness about IMCI drugs and varied perceptions about drug availability \\
& Inadequate monitoring and supervision \\
& Hindrances in the information system \\
& Corruption- affecting the practice of IMCI trained physicians \\
\hline
\end{tabular}

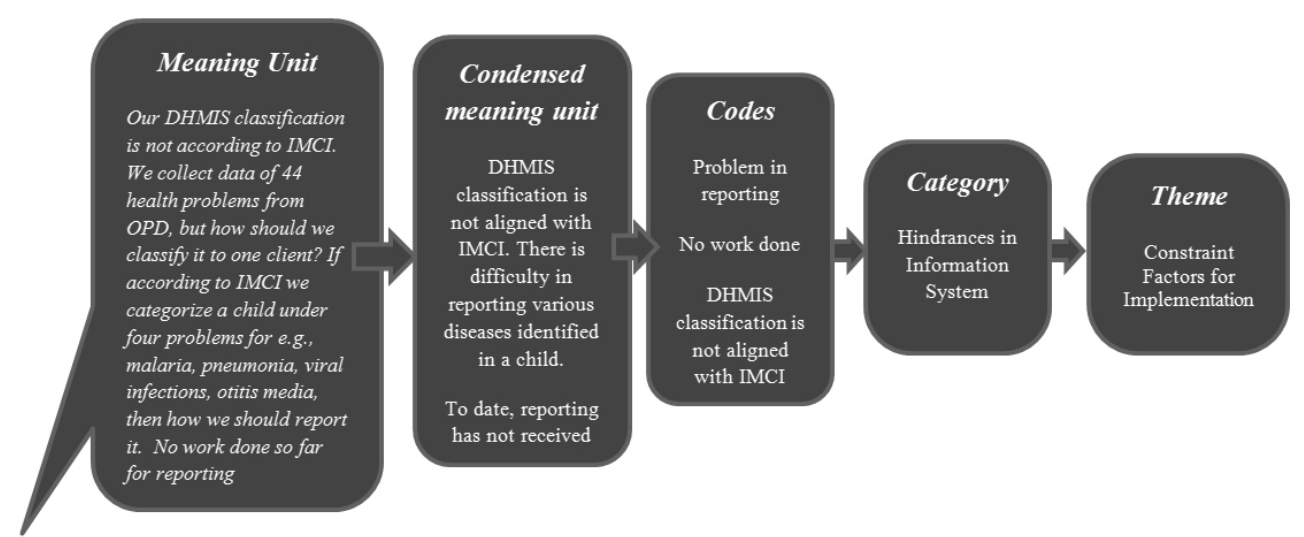

Figure 1. Analysis process, moving from meaning units to theme. 


\section{Findings}

Textual analysis was grouped into two broad themes: (1) support factors and (2) constraint factors for IMCI implementation.

\subsection{Theme 1: Support Factor for IMCI Implementation Significance of IMCI Strategy}

In most interviews, respondents believed that the strategy plays an important role in managing acute illnesses in young children and most of the respondents were aware of the aim of IMCI strategy. The strategy was perceived as the "best option for under-five year aged children", "good program for the benefit of the community" and "beneficial for doctors".

"This strategy is wonderful...it is for the first time that public health fraternity has come to design a strategy which is touching upon human rights... here we are actually addressing a child and not a disease. For the last 60 years, we have been running after disease and now we are actually taking care of the overall child". (P2; Provincial level respondent)

Respondents also felt that the strategy provide guidance to doctors which facilitates in diagnosis and management of children.

"...the strategy tells you how to diagnose the baby and what treatment plans you should offer.. . right diagnosis and right treatment at the spot is given by doctors. Without a stethoscope in hand, you can diagnose whether or not the child is suffering from a disease". (P1; Provincial level respondent)

However, not all respondents were aware of the objectives of the strategy and asserted that they should be trained in IMCI strategy.

\subsection{Theme 2: Constraint Factors for IMCI Implementa- tion}

\subsubsection{Disparities in views towards lead role in implemen- tation}

Planners and implementers differ in their views about the accountability and the lead role in implementation. Planners felt that the district health management authority should undertake the ultimate responsibility for implementation of the strategy. A provincial level respondent mentioned that guidance was provided to the district leadership for IMCI implementation.

"I think we are clear that we are going to train staff all over Sindh, but the responsibility for implementation lies with EDO-H. EDO-H has been provided with the implementation guidelines by MNCH program". (P1; Provincial level respondent)

On the other hand, a key district level implementer com142 mented on the lack of support received from the provincial level and reflected his helplessness in various matters pertaining to implementation.

"At implementation level, no one is helping us...the ball is thrown into our court after providing training by MNCH Program...[Although] Professor X has done his job, but MNCH program is responsible for implementation...”. (D1; District level respondent)

\subsubsection{Perception about IMCI trained physicians' willing- ness to practice IMCI strategy}

Majority of the respondents felt that trained IMCI physicians are unwilling to practice the strategy. Identified factors contributing to physicians' apathy in implementation of strategy were: lack of motivation, shyness and unwillingness to accept the strategy itself.

A few of the respondents admitted that receiving stipend was a major stimulus for physicians during IMCI training, however, its effect weaned off after training.

"These doctors have to run OPD, but they are unwilling to work in pediatric OPD...they are not motivated and are unwilling. For training, everyone is interested because money (stipend) is given. Doctors spend 11-15 days of training in Karachi but once they return, they say that it's very difficult we don't want to practice that". (D3; District level respondent)

Another respondent mentioned that:

"Motivation of the doctors was actually the per diem (stipend). The motivation in the group of Matiari is to become the facilitator and earn some money. But the motivation and pride in helping and saving a child has not seeped into them. This can only come from behavior change communication". (P2; Provincial level respondent)

Another issue was the acceptance of the strategy as well as physicians' lack of compliance with the strategy protocol also surfaced, as stated by one of the respondent.

"...to date, we are not ready to use the drug rationally, we are not ready to counsel the mother, we are not ready to commit with the mother that I would be here when you come after two days..." (P2; Provincial level respondent)

Conversely, few respondents stated that physicians are committed to implement the strategy and they need support staff and essential logistics to practice the strategy.

\subsubsection{Inadequate logistic support}

Respondents largely expressed their dissatisfaction over the required logistic support for IMCI implementation at health care facilities. In context of essential supplies and equip- 
ment, a few respondents specifically mentioned the absence of weighing scale and mother counseling cards.

Others highlighted the need for IMCI reporting tools i.e. a data collection tool for recording purpose. And an ambiguity towards the printing of the recording tools was also highlighted.

"There is unavailability of data collection tools, forget about nebulizers, $0.1 \mathrm{~kg}$ precision weighing scales, Hb meter, availability of drugs, thermometer, tongue depressor and torches; only think about data collection tool. A two pager, required to be filled to assess and classify a child. To date, nobody has decided who will print it. We have arranged reporting tool from donors and philanthropist...”. (P3; Provincial level respondent)

In context of ensuring required infrastructure and logistic support, discrepancies exist among implementers and planners. Planners at provincial level hold district leadership and facility in-charge responsible for the inadequate support. On the other hand, district level implementers were of the opinion that the accountability lies with the provincial $\mathrm{MNCH}$ program for the required logistic support for IMCI implementation.

\subsubsection{Lack of awareness about IMCI drugs and varied per- ceptions about its availability}

Half of the respondents were unaware of the list of the essential IMCI drugs. A planner at provincial level shared that they rely on district pediatricians' guidance in the selection of the drugs for under-five case management.

"I am not aware about IMCI basic supplies, equipment and drugs. Pediatricians are there in our resource group to suggest the list of drugs. If you (asking from interviewer) can recommend particular drug, we can include them in our list". (P4; Provincial level respondent)

Respondents also vary in their perceptions about the availability of essential IMCI drugs at the PHC facilities. Half of the respondents assumed that drugs are available at the center and are being utilized by the physicians.

"I think medicine is available...I have not received any list of IMCI drugs, I only know Amoxicillin. It is the responsibility of facility In-charge to keep the stock of drugs and send request to us". (D1; District level respondent)

\subsubsection{Inadequate monitoring and supervision}

Monitoring and supervision was considered to be an "essential aspect" of implementation and was perceived to be inadequate in the district health care system. Respondents however, varied in their perceptions about monitoring of the trained physicians.

Published by Sciedu Press
"Currently monitoring of trained doctors is functional at the district level. They are monitored and supervised at district level with the help of EDO-H...”. (P1; Provincial level respondent)

Contrary to this, district level respondents mentioned that monitoring and supervision of trained workforce is inadequate in district health care system and respondents at district level urged the need for monitoring system. It was communicated that a focal person has visited the PHC facilities and has assessed IMCI recording forms filled by physicians. However, physician's case management skills were not observed. Identified reasons for inadequate monitoring and supervision were unavailability of district supervisor, budget constraints and absence of monitoring checklist. Furthermore, absence of capacity for follow-up monitoring visit was also highlighted.

"Dr. X pays monitoring visits once a month, but he is not trained for monitoring a trained IMCI doctor...Follow-up visits after training is yet to be implemented in this part of the world". (P5;Provincial level respondent)

\subsubsection{Hindrances in information system}

Respondents expressed issues in reporting of under-five year old assessment according to IMCI criteria. It was communicated that information system for IMCI reporting is not in place. At district level, a form for monthly reporting had been formulated on which physicians were encouraged to report IMCI managed cases. Furthermore, it was also highlighted that District Health Management Information System (DHMIS) is not in accordance with IMCI classification, which creates hindrances in reporting.

"Our DHMIS classification is not according to IMCI. We collect data of 44 health problems from OPD, but how should we classify it to one client? If according to IMCI we categorized a child into four problems for e.g., malaria, pneumonia, viral infections, otitis media, then how we should report it... No work done till to date for reporting". (D2; District level respondent)

\subsubsection{Corruption- affecting the practice of IMCI trained physicians}

A glimpse of a corrupt health care system was apparent which further worsens the existing scenario. In view of a provincial level respondent, political influence in district health system affects the service delivery by trained physicians.

"Current political influences interfere with implementation in this part of the world. When a trained person returns to his facility, a telephone call is received which favors his appointment as a Surveillance Coordinator or to any other program in the district". (Provincial level respondent) 
Likewise, a respondent at district level also felt an undue pressure on District Health Management Team (DHMT) for not utilizing the services from trained physicians.

"A telephone call pressurizes us for not taking any work from IMCI trained doctor. ...Even if you try to correct things, there will be a pressure that you are disturbing our men...”. (DI; District level respondent)

\section{Discussion}

The study elucidates on the complex health system issues faced during IMCI implementation in district Matiari, Sindh. The objectives and importance of the strategy is universally appreciated among respondents, but implementation has been constrained by multiple issues in the district health system. Above all, differences in planners and implementers' perceptions over important aspects constrained the smooth functioning of the strategy.

The importance of collaboration between stakeholders stands out, as demonstrated by the disparities in views towards accountability and leadership in strategy implementation. Planners at provincial level considered DHMT responsible for the implementation. Whereas, implementers at the district level voiced their helplessness and held provincial $\mathrm{MNCH}$ program accountable for IMCI implementation process. This could be attributed to communication gap amongst the involved stakeholders. WHO-IMCI planning guide recommends national and provincial level stakeholders to involve districts in the planning exercise, thereafter, the responsibility lies with districts to initiate planning and implementation of the strategy. ${ }^{[21]}$ India responded to this problem by having planning meetings and developing operational guidelines to facilitate implementation of the strategy. ${ }^{[7]}$ Further, it was also found that few important stakeholders were unclear in their understanding of the strategy and thus expressed the need for training. In this regard, WHO recommends capacity building of key MoH personnel in IMCI training beside planning and adaptation procedures. ${ }^{[8]}$ Lack of capacity building of the involved stakeholders in IMCI strategy has been documented from other countries too. Kazakhstan addressed this problem by developing training strategy for implementation. ${ }^{[7]}$ Similar approach can be carried out in Pakistan by involving provincial and district level partners.

The study also highlights inadequate service delivery support at PHC facilities such as unavailability and inadequacy of reporting forms and other essential supplies needed for the uninterrupted service delivery. Findings from other developing countries have also reported unavailability and inadequacy of essential supplies which acted as a major constraint in IMCI implementation. ${ }^{[12,22,23]}$ Conversely, a study in China exhib- ited increased availability of supplies and equipment with regards to IMCI implementation. ${ }^{[24]}$ Although major responsibility in this regard lies with DHMT to provide required logistic support, however keeping in view the complex situation and pronounced communication gap between district and provincial level stakeholders, we recommend Council of Common Interest at federal level to intervene and provide necessary support.

Monitoring is considered to be a crucial element of any health system, and is essential to improve the quality of care. Discrepancies in views among planners and implementers also reported over monitoring and supervision of trained workforce. District monitoring and supervisory mechanism was found to be non-functional due to various administrative and logistic issues including lack of capacity for monitoring visits, financial constraints and absence of monitoring checklist etc. This questions the quality of service delivery by trained physicians at PHC centers. Countries such as Bangladesh, Bolivia, Brazil and Cambodia have also reported weak supervision to IMCI trained workforce. ${ }^{[10]}$ In this regard, WHO strongly emphasize follow-up visits to all trained workforce post training (within 4-6 weeks). ${ }^{[25]}$ This ideally should be carried out by DHMT after their capacity building by provincial MNCH. Weak monitoring and supervision has been reported from other countries with regards to IMCI implementation too. ${ }^{[23]}$ Countries however, came up with strategies to address the problem. For instance, in Moldova, monitoring and evaluation center for child health was developed to keep a track on IMCI related activities. ${ }^{[7]}$

Stakeholders' lack of awareness regarding the essential IMCI drugs and their uncertainty about drug availability at health facilities indicate knowledge gap on the pre-requisite for strategy implementation. And this further co-relates with lack of monitoring visits in the district. Findings obtained from the larger quantitative arm of the study indicate insufficiency of IMCI drugs and supplies at PHC facilities. Mean availability of drugs ranges from $45.8 \%$ to $56.7 \%$ indicating that none of the facility had all the required drugs. ${ }^{[19]}$

IMCI trained physicians were generally perceived as unwilling to practice the strategy. Their motivation appeared to be influenced by and limited to the per diem received during training. Another contributing factor towards lack of motivation was inadequate logistic support at the PHC health facilities. The negative perception of stakeholders is subject to critique, keeping in view the inadequate monitoring and supervision which indicates stakeholders' lack of insight on IMCI trained physicians' performance. Interestingly, the findings obtained from the larger study didn't support stakeholder's perceptions about trained physicians' attitude, be- 
cause physicians expressed willingness to apply the case management protocols according to IMCI strategy. ${ }^{[19]}$ In this regard, DHMT needs to ensure that trained workforce is motivated to perform the expected tasks, as described for the program implementation at health facility level.

Public health systems are often plagued by favoritism and corruption $^{[26]}$ and same holds true in this scenario where inefficient utilization of the trained workforce was reported. The perceived political influences tend to restrict the practice of trained physicians and further worsen the scenario. This further argues the stakeholders' negative perceptions about the trained workforce.

To the best of our knowledge, studies have not been conducted to assess IMCI health workers' motivation; however studies reporting health workers' compliance with IMCI algorithm can be taken as a proxy. Study in Egypt illustrated that trained workers met the criteria for quality care by following IMCI criteria. ${ }^{[27]}$ On the other hand, few countries reported low health workers' compliance after training. ${ }^{[11,28]}$ Therefore, we suggest more studies to reach a conclusive agreement on health workforce motivation to implement the strategy. Furthermore, stakeholders' perception about physicians' unenthusiastic and demotivated attitude toward strategy implementation itself is arguable owing to inadequate logistic support at the facility.

The issue also revolved around reporting and documentation in DHMIS. Reporting was not perceived to be aligned with IMCI classification. Inconsistencies between IMCI classification and routine disease reporting system has been documented from other developing countries also. ${ }^{[7]}$ In context of devolved health system, the provincial health department needs to recommend procedures to help health workers meet the Health Information System (HIS) reporting requirements adequately after IMCI training. Of the several options suggested to resolve IMCI-HIS incompatibilities; we recommend modifications in existing DHMIS to include IMCI classification to track under-five morbidities and mortalities. $^{[29]}$

This study in general reflects an inadequate health system support for the strategy implementation. District health system is characterized by an inadequate logistic support at the facility, weak monitoring and supervisory mechanism and hindrances in IMCI reporting system. Furthermore, lack of synchronization amongst planners and implementers is indicative of poor planning and communication gap over key aspects in the implementation. Inadequate health system support for IMCI implementation noted in our study has also been reported from other developing countries around the world. ${ }^{[8,10]}$ On the other hand, IMCI implementation in Egypt is an exceptional case, health system support was strengthened concurrently with IMCI expansion activities and it ultimately showed significant reduction in under-five mortality. ${ }^{[30]}$

The complex health system issues demonstrated in this study can be overcome by aligning planners and implementers understanding around important aspects in the implementation process. Districts have the mandate for IMCI implementation under provincial $\mathrm{MNCH}$ program, we therefore recommend provincial $\mathrm{MNCH}$ program to initiate a participatory planning process by involving planners and implementers. This will also provide an opportunity to address and resolve the identified issues in IMCI implementation. The accountability issues highlighted in this study can be addressed by detailed description of the expected roles and responsibilities to provincial and district leadership by $\mathrm{MNCH}$ program. The program also needs to empower the DHMT towards effective and efficient implementation of the strategy. This requires capacity building of district leadership in understanding IMCI strategy, monitoring and supervision of trained manpower and providing required logistic and financial support to facilitate the implementation process. All these recommendations are significant in context of post-devolution scenario in Pakistan, where federal MoH has been devolved to provincial ministries. ${ }^{[14]}$ Keeping in view the discrepancies which surfaced between provincial and district health actors, we also suggest Council of Common Interest (CCI) at federal level (which came into existence in post-devolution phase) to oversee the entire implementation process in light of these recommendations.

This study provides evidence to strengthen the health system support from implementers and planners' perspective; an avenue which has not been evaluated in the past in our country and limited evidence is available in other developing countries. The inter connectedness of the issues reflected in this district can also be generalized to other districts in the province as well. Future studies can evaluate the fulfillment of required health system support and its cumulative effect on IMCI case management at public sector PHC facilities.

Steps taken to ensure reliability in the study ${ }^{[31]}$ include: purposive selection of the participants, interviews were conducted in respondents' language of choice (three out of eight stakeholders' interviews were conducted in English, while the remaining were conducted in Urdu). For analytical constructs, codes and categories were labeled and discussed amongst the study core team. ${ }^{[19]}$ Findings from a qualitative work are specific to small number of particular environment and individuals; therefore, it is not possible to generalize findings to other population. Also the purpose of qualitative 
studies is not to generalize the findings, but to generate indepth understanding of the problem under investigation. ${ }^{\text {[32] }}$ Available literature on transferring findings/generalizability in qualitative enquiry suggests providing sufficient contextual details about the work undertaken to allow readers to make a transfer. ${ }^{[32]}$ Findings from this study can be transferred to other districts in Sindh province which share similar socio-demographics characteristics and management structure.

In context of transferability i.e., the extent to which the findings can be transferred to other settings, the required details are mentioned including description of the context, data col- lection methods, selection of participants, presentation of findings with quotations and analysis method. ${ }^{[20,32]}$

The study interviewed limited number of stakeholders' involved in IMCI planning and implementation process. In our study's context the identified stakeholders were purposively chosen as virtue of their roles and responsibilities in the IMCI implementation to yield in-depth understanding of the study objective. Furthermore, qualitative studies are not concerned with "how many" it's rather the in-depth understanding which is of significance. ${ }^{[33]}$ Key recommendations discussed above are categorized at two major levels (provincial MNCH and DHMT) and are presented in Table 3.

Table 3. Health system wide recommendations

\begin{tabular}{|c|c|c|}
\hline Levels & $\begin{array}{l}\text { Provincial Maternal Neonatal and Child Health } \\
\text { Program (MNCH) }\end{array}$ & District Health Management Team (DHMT) \\
\hline Recommendations & $\begin{array}{l}\text { - Conduct participatory planning process by } \\
\text { involving planners and implementers which can } \\
\text { lead to transparency in communication amongst } \\
\text { the involved partners. } \\
\text { - Provide detailed description of the expected roles } \\
\text { and responsibilities to provincial and district } \\
\text { leadership. } \\
\text { - Organize capacity building workshops for district } \\
\text { and provincial stakeholders. } \\
\text { - Oversee the entire implementation process. } \\
\text { - Assess the capacity of key provincial and district } \\
\text { level leadership on frequent intervals. }\end{array}$ & $\begin{array}{l}\text { - Initiate planning and implementation } \\
\text { of the strategy. } \\
\text { - } \quad \begin{array}{l}\text { Ensure availability of required IMCI } \\
\text { logistics (chart booklets, supplies, } \\
\text { equipment and drugs). }\end{array} \\
\text { - } \quad \begin{array}{l}\text { Ensure availability of trained human } \\
\text { resource and boost their motivation. }\end{array} \\
\text { - Adequate monitoring and supervision } \\
\text { of trained manpower. } \\
\text { Modify existing DHMIS to include } \\
\text { IMCI classification to track } \\
\text { under-five morbidities and mortalities }\end{array}$ \\
\hline
\end{tabular}

Note $^{*}$ Recommendation are mainly listed at two levels: district and provincial levels after abolishment of federal MoH to provinces ${ }^{[14]}$.

\section{Conclusion}

Study demonstrates inadequate health system support for IMCI implementation in Matiari district. To conclude, there is a sound understanding of the significance of IMCI strategy amongst stakeholders in the district. Discrepancies were evident amongst planners and implementers towards important aspects in implementation; indicating the communication gap. This needs to be resolved through participatory planning process. There are a number of important but potentially soluble barriers to implementation which can be dealt by provincial and district health managers in light of above recommendations. We therefore emphasize provincial
MNCH program to synchronize district and provincial leadership and provide necessary support to DHMT to overcome the various constraints faced in IMCI implementation. Most importantly, taking on board district and provincial planning and implementation partners and aligning their understanding of the implementation process and providing required logistic support in the entire process. Although Pakistan is far behind achieving MDG 4; young lives can still be saved by overcoming the hurdles in the implementation of IMCI strategy in light of the study's recommendations.

\section{CONFLICTS OF INTEREST Disclosure}

The authors declare no conflict of interest.

\section{REFERENCES}

[1] World Health Organization. Global Health Observatory- Under Five Mortality. 2013. Available from: http://www. who.int/gho/ch ild_health/mortality/mortality_under_five_text/en/

[2] World Health Organization. The partnership for maternal, neonatal and child health. Child Mortality. Available from: 
http://www. who.int/pmnch/media/press_materials/fs /fs_mdg4_childmortality/en/

[3] World Health Organization. Child health and development. IMCI Strategy. Available from: http://www. emro. who.int/child-h ealth/imci-strategy/imci-strategy/All-Pages.html

[4] World Health Organization. Maternal Newborn Child and Adolescent Health. Integrated Management of Childhood Illness (IMCI). Available from: http://www. who.int/maternal_child_adole scent/en/

[5] World Health Organization. Maternal, newborn, child and adolescent health. Integrated Management of Childhood Illness (IMCI). Available from: http://www. who.int/maternal_child_adole scent/topics/child/imci/en/

[6] Ahmed HM, Mitchell M, Hedt B. National implementation of Integrated Management of Childhood Illness (IMCI): policy constraints and strategies. Health Policy. 2010; 96: 128-33. PMid: 20176407. http://dx.doi.org/10.1016/j.healthpol .2010.01.013

[7] Goga AE, Muhe LM. Global challenges with scale-up of the integrated management of childhood illness strategy: results of a multicountry survey. BMC Public Health. 2011; 11: 503. PMid: 21708029. http://dx.doi.org/10.1186/1471-2458-11-503

[8] Lambrechts T, Bryce J, Orinda V. Integrated management of childhood illness: a summary of first experiences. Bull World Health Organ 1999; 77: 582-94.

[9] Walter ND, Lyimo T, Skarbinski J, et al. Why first level health workers fail to follow guidelines for managing severe disease in children in the Coast Region, the United Republic of Tanzania. Bull World Health Organ. 2009; 87: 99-107.

[10] World Health Organization. Department of Child and Adolescent Health and Development. The Multi-country Evaluation of IMCI Effectiveness Cost and Impact (MCE). Progress Report May 2001-April 2002. Geneva, Switzerland. Report No. WHO/FCH/CAH/02.16.

[11] Arifeen SE, Bryce J, Gouws E, et al. Quality of care for under-fives in first-level health facilities in one district of Bangladesh. Bull World Health Organ. 2005; 83: 260-7. PMid: 15868016.

[12] Huicho L, Davila M, Campos M, et al. Scaling up integrated management of childhood illness to the national level: achievements and challenges in Peru. Health Policy Plan. 2005; 20: 14-24. PMid: 15689426. http://dx.doi.org/10.1093/heapol/czi002

[13] World Fact Book for Pakistan. Available from: https: //www.cia.gov/library/publications/the-world-factb ook/geos/pk.html

[14] Pildat An Analysis. Health and the 18th Constitutional Amendment. April 2011. Available from: http://www.pildat.org/Publica tions/publication/publichealth/PILDATAnalysis-Hea lthandthe18thConstitutionalAmendments.pdf

[15] World Health Organization. Regional Health System Observatory. Health System Profile of Pakistan. Available from: http://apps.w ho.int/medicinedocs/documents/s17305e/s17305e.pdf

[16] World Health Organization. Integrated Management of Childhood Illness (IMCI) in Pakistan. Available from: http://www.emro.who.int/child-health/strategyimpl ementation/implementation-of-imci-in-pakistan.html

[17] World Health Organization. Child and adolescent Health and Development. Implementation of IMCI in Pakistan. Available from: http: //rho.emro. who.int/rhodata/node.main.A189?lang=en

[18] You D, New JR, Wardlaw $T$, et al. Levels and Trends in Child Mortality. Estimates developed by the UN Interagency Group for Child Mortality. 2012; 1-32. Available from: http://www.who.int/maternal_child_adolescent/ documents/levels_trends_child_mortality_2012/en/
[19] Pradhan NA, Rizvi N, Sami N, et al. Insight into Facility-based Integrated Management of Childhood Illness Childhood Illness Strategy in a Rural District of Sindh, Pakistan. Global Health Action. 2013; 6: $1-15$.

[20] Graneheim UH, Lundman B. Qualitative content analysis in nursing research: concepts, procedures and measures to achieve trustworthiness. Nurse Educ Today. 2004; 24: 105-12. PMid: 14769454 http://dx.doi.org/10.1016/j.nedt.2003.10.001

[21] World Health Organization. Department of Child and Adolescent Health and Development. IMCI Planning Guide. Gaining experience with the IMCI strategy in a country. Available from: http://www.who.int/maternal_child_adolescent/ documents/chs_cah_99_1/en/

[22] Pariyo GW, Gouws E, Bryce J, et al. Improving facility-based care for sick children in Uganda: training is not enough. Health policy and planning. 2005; 20: 58-68. http://dx.doi.org/10.1093/h eapol/czi051

[23] World Health Organization. The analytic review of the Integrated Management of Childhood Illness strategy. Geneva. 2003. Available from: http://apps.who.int/iris/bitstream/10665/ 42965/1/9241591730.pdf

[24] Zhang Y, Dai Y, Zhang S. Impact of implementation of Integrated Management of Childhood Illness on improvement of health system in China. J Paediatr Child Health. 2007; 43: 681-5. PMid: 17854453. http://dx.doi.org/10.1111/j.1440-1754.2007.01187.x

[25] World Health Organization. Department of Child and Adolescent Health and Development. Guidelines for follow up after training. 1999. Available from: http://www. union-imdp.org/images/resources/Int egrated $\% 20$ management $\% 20$ of $\% 20$ childhood $\% 20$ illness $\% 20$ for $\% 20$ irst-level $\% 20$ health\%20workers.pdf

[26] European Commission. Study on Corruption in Health Sector HOME/2011/ISEC/PR/047-A2 October 2013. Available from: http://ec. europa.eu/dgs/home-affairs/what-is-new/n ews/news/docs/20131219_study_on_corruption_in_the _ healthcare_sector_en.pdf

[27] Nguyen DT, Leung KK, McIntyre L, et al. Does Integrated Management of Childhood Illness (IMCI) Training Improve the Skills of Health Workers? A Systematic Review and Meta-Analysis PLoS One. 2013; 8(6): 1-13. http://dx.doi.org/10.1371/journal . pone. 0066030

[28] Horwood C, Vermaak K, Rollins N, et al. An evaluation of the quality of IMCI assessments among IMCI trained health workers in South Africa. 2009; PLoS One 4: e5937. http://dx.doi.org/10.1371 /journal.pone. 0005937

[29] Rowe AK, Hirnschall G, Lambrechts T, et al. Linking the integrated management of childhood illness (IMCI) and health information system (HIS) classifications: issues and options. Bull World Health Organ. 1999; 77(12): 988-95. PMid: 10680246.

[30] Rakha MA, Abdelmoneim AN, Farhoud S, et al. Does implementation of the IMCI strategy have an impact on child mortality? A retrospective analysis of routine data from Egypt. BMJ Open. 2013; 3:e001852, 1-10. PMid: 23355663. http://dx.doi.org/10.11 36/bmjopen-2012-001852

[31] Ali AM, Yusof H. Quality in qualitative studies: the case of validity, reliability and generalizability. Issues Soc Environ Account. 2011; 5(1/2): 25-64.

[32] Shanton AK. Strategies for ensuring trustworthiness in qualitative research project. Education for Information. 2004; 22: 63-75.

[33] Baker SE, Edwards R. How many qualitative interviews is enough. National Center for Research Methods. 2012; 1-43. 